\title{
De Medellín a Aparecida: marcos, trajetórias, perspectivas da Igreja Latino-americana ${ }^{1}$
}

Ana Maria Tepedino

\section{Introdução}

Considero muito importante estarmos celebrando os 42 anos da Conferência de Medellín, que marcou de tal maneira nosso continente, por isso, o consideramos evento fundante da Igreja latino-americana. Como é a Igreja que Medellín propôs? Qual o rumo eclesial que ela continua marcando? Qual a sua atualidade? O que é irreversível na sua proposta? O que ainda não foi vivido?

A importância da celebração dos 42 anos de um documento me parece a seguinte: cristãos-ãs, teólogos-as, magistério retomam, rememoram, reinterpretam, resignificam as afirmações e desta forma se recria um imaginário teológico ${ }^{2}$. Assim como falamos em imaginário do Vaticano II, que ultrapassa os seus 16 documentos, o mesmo podemos afirmar de Medellín. A relevância deste procedimento é que se constitui em excelente ocasião de balanço e possibilidade de criar uma nova mentalidade, que recupere o entusiasmo e efervescência eclesial da época da Conferência, ou seja, a criação de um conjunto de idéias, modelos, valores, comportamentos, atitudes, que as pessoas adotaram e dentro dos quais estes fatores se tornam significativos

\footnotetext{
${ }^{1}$ Esse artigo é fruto da conferência do Ciclo de Conferências na Universidade Unisinos - IHU.

${ }^{2}$ Cf. G. LAFONT, Imaginar a Igreja Católica, São Paulo, Loyola, 2006, trabalha esta categoria de imaginário, pois não se pode pensar totalmente a Igreja sem fazer intervir um mundo das imagens, das emoções, das experiências, dos afetos, pois a Igreja é uma tem uma dimensão objetiva, fora de nós, mas também uma dimensão subjetiva, dentro de nós.
} 
e inteligíveis. O Concílio nos propôs um "projeto" de Igreja, que Medellín re-cria na América Latina, e, isto, é uma tarefa que afeta, não apenas a nossa geração, mas também às gerações futuras. Trabalham-se elementos novos que substituem visões anteriores e possibilitam a gestação de novas perspectivas, mesmo que seja lentamente. Afinal, Medellín, foi considerada um novo Pentecostes, o latino americano.

Antes de refletirmos sobre a Eclesiologia Latino americana permitamme um rápido olhar sobre dois pontos nevrálgicos do Vaticano II- sua postura com relação aos leigos-as, dentro da perspectiva da Eclesiologia total e sua abertura com relação ao mundo, que serão de fundamental importância para entender a igreja latino americana ${ }^{3}$.

\section{O Vaticano II e os Leigos: a Lumen Gentium}

No bojo do processo de transformação dos anos 60, ocorre o Concílio Vaticano II, convocado pelo Papa João XXIII para repensar a identidade e a missão da Igreja Católica e sua relação com o mundo, ou seja, para que esta dialogasse com os problemas da época.

Para nós, leigos e leigas o Vaticano II se constituiu numa experiência de valorização e reconhecimento, um verdadeiro Pentecostes, pois a constituição dogmática, Lúmen Gentium que repensou a identidade da Igreja, colocou em primeiro lugar- o que era comum a todos-as na igreja católica- ou seja, a condição cristã, que em virtude do sacramento do Batismo nos constitui a todos-as como equivalentes dentro do Povo de Deus, possibilitando, aos leigos e leigas, um novo estatuto dentro da Igreja Católica. Colaborou para nos restituir a situação, que tínhamos na Igreja dos primórdios. Nunca é demais lembrar que esta perspectiva aparece no capítulo II, onde se reflete sobre o Povo de Deus, antes de se refletir sobre a Hierarquia e o Episcopado (capitulo III), e ainda volta a falar dos leigos no capítulo IV.

O documento busca oferecer uma definição positiva de leigo:

"Por leigos entende-se aqui todos os cristãos, que não são membros da sagrada ordem ou do estado religioso, reconhecido pela Igreja, isto é, os fiéis que, incorporados em Cristo pelo Batismo, constituidos Povo de Deus e tornados participantes, a seu modo, da função sacerdotal, profética e real de Cristo, exercem, pela parte

\footnotetext{
${ }^{3}$ Se eu fosse homem e padre teria dado preferência ao tema da colegialidade que é o terceiro ponto nevrálgico do Vaticano II.
} 
que lhes toca, a missão de todo o povo cristão na Igreja e no mundo" 4 .

Dentro desta perspectiva, é reconhecido a todos os batizados a mesma igualdade e dignidade cristãs; a mesma vocação e missão. Ocorre uma valorização dos leigos-as, que participam em paridade com os outros estados de vida, como protagonistas da missão da Igreja, como fermento no mundo. Dentro deste panorama que chama os leigos à corresponsabilidade na Igreja, vão aparecer as mulheres:

"Com efeito, se é verdade, que todas as coisas que se disseram a respeito do Povo de Deus se dirigem igualmente aos leigos, aos religiosos e aos clérigos, algumas, contudo, pertencem de modo particular aos leigos, homens e mulheres, em razão de seu estado e missão; e os seus fundamentos, devido às circunstâncias especiais de nosso tempo, devem ser mais cuidadosamente expostos. Os sagrados pastores conhecem, com efeito, perfeitamente quanto os leigos contribuem para o bem de toda a igreja. Pois eles próprios sabem que não foram instituídos por Cristo para se encarregarem por si sós de toda a missão salvadora da igreja para com o mundo"s.

A missão salvífica de Cristo no mundo é levada a cabo não somente pelos ministros ordenados, mas também, por todos os fiéis leigos: homens e mulheres. Aqui aparece a igualdade fundamental que deve existir na comunidade cristã entre todos os membros, que retoma a fórmula prébatismal de G1 3,28: "Já não há judeu, nem grego, nem escravo nem Senhor, nem homem nem mulher, pois sois Um no Cristo Senhor”. Homens e mulheres leigos recebem o mesmo múnus e são convidados a viver a missão de levar ao mundo a Boa Nova de Jesus. São reconhecidos como os evangelizadores privilegiados, porque existem lugares em que a Igreja só pode chegar aonde eles e elas vivem e trabalham. A hierarquia reconhece o bem que estes cristãos fazem e deve valorizar esta encarnação nas diferentes realidades onde estão presentes, "como sal da Terra" .

Os números 32 e 33 da GS afirmam que todos são chamados à santidade, e que o chamado de participação na missão é para todos".

\footnotetext{
${ }^{4}$ LG 31; cf. tb. AA 2-3, 9.

${ }^{5}$ LG 30 .

${ }^{6} \mathrm{LG} 33$.
} 
Portanto, as mulheres têm o mesmo direito e dever, a mesma dignidade e responsabilidade que o homem na missão evangelizadora da Igreja e na transformação e humanização do mundo, segundo os valores do Reino ${ }^{7}$. Esta perspectiva aparece de modo muito claro na Gaudium et Spes. O papa João Paulo II irá enfatizar estes pontos na Christefideles Laici $^{8}$.

\section{A Gaudium et Spes: a Igreja volta-se para o mundo}

Olhando hoje este documento, consideramos sua antropologia integra$\mathrm{da}$, que considera a pessoa humana "na sua unidade e totalidade, corpo e alma, coração e consciência, inteligência e vontade", $e$ se percebe que ele explicita questões atuais, como as relações de gênero.

A leitura da realidade a partir da categoria de gênero permitiu entender que as relações entre homem-mulher, homem rico e homem pobre, mulher escolarizada e mulher analfabeta estabelecem relações sociais de poder, que existem na sociedade. Enquanto os homens foram socializados para serem seres políticos, as mulheres foram socializadas para serem seres domésticos. Então, não é a natureza que determina esta diferença, mas, esta é construída culturalmente. As análises da teoria de Gênero nos permitiram entender que as relações entre homens e mulheres; entre classes sociais, entre etnias, e entre idades são relações de poder, que obedecem a uma socialização cultu$\mathrm{ral}^{10}$. Nós incorporamos o masculino e o feminino, o ser de classe média ou classe pobre, o ser universitário ou ser sem estudos, aprendendo comportamentos, hábitos, maneiras de pensar de acordo com a definição social de cada uma destas diferenças: o que é ser homem, branco, ou negro, universitário ou analfabeto, rico ou pobre, ou o que é ser mulher branca, ou negra, de classe média ou de classe popular, com terceiro grau ou primário. Não é a natureza que afirma que o mundo público é para os homens, e o privado para as mulheres, mas a cultura. Desde cedo, as meninas são treinadas para serem donas de casa, para cuidar das crianças, para fazer serviço doméstico. Ao mesmo tempo, meninos são treinados para ser bons trabalhadores, bons profissionais, e para ter responsabilidades públicas. A conclusão é clara: a divisão social de trabalho é o resultado de uma construção cultural, e por isso, pode ser desconstruída. Neste sentido, é profética a afirmação:

\footnotetext{
${ }^{7}$ Cf. D. BOROBIO, Misión y ministerios laicales, Salamanca, Sigueme, 2001, p.97.

${ }^{8}$ JOÀO PAULO II, Exortação Apostólica, Christifideles Laici, (ChL), 30/12/1988, nos. 10, 23; 51.

${ }^{9} \mathrm{GS} 3$.

${ }^{10}$ Cf. G. RUBIN, The traffic on women. Notes on the political economy of sex, 1975. Este livro foi considerado a moldura para a Teoria Analítica de Gênero.
} 
"Os povos oprimidos pela fome interpelam os povos mais ricos. As mulheres reivindicam a paridade de direitos com os homens, onde ainda não a alcançaram. Os operários e os camponeses querem não apenas ganhar o necessário para viver, mas desenvolver, graças ao trabalho, as próprias qualidades, mais ainda, querem participar na organização da vida econômica, social, política e cultural. Pela primeira vez na história dos homens, todos os povos têm já a convicção de que os bens da cultura podem e devem estender-se efetivamente a todos $" 11$.

Embora a constituição pastoral mencione apenas poucas vezes as mulheres, o faz sempre relacionalmente, quer seja no contexto do relato da criação $^{12}$, dentro da relação conjugal e familiar ${ }^{13}$ quer seja na luta contra toda e qualquer discriminação:

mas, deve superar-se e eliminar-se, como contrária à vontade de Deus, qualquer forma social ou cultural de discriminação, quanto aos direitos fundamentais da pessoa, por razão do sexo, raça, cor, condição social, língua ou religião. É realmente de lamentar que esses direitos fundamentais da pessoa ainda não sejam respeitados em toda parte. Por exemplo, quando se nega à mulher o poder de escolher livremente o esposo ou o estado de vida ou de conseguir uma educação e cultura iguais ao homem ${ }^{, 14}$.

O documento também reconhece a realidade da vida das mulheres e afirma ainda, que:

"as mulheres já trabalham em quase todos os setores da vida. É conveniente, porém, que possam assumir plenamente de acordo com a própria indole, o papel que lhes toca. É dever de todos reconhecer e promover a participação específica e necessária da mulher na vida cultural ${ }^{\prime \prime 15}$.

${ }^{11}$ GS 9.

12 GS 43.

${ }^{13}$ GS 47-52.

${ }^{14}$ GS 29.

${ }^{15}$ GS 60 . 
Sabemos que estes pronunciamentos ficam, na maioria das vezes no papel, porém sem o Vaticano II, não estaríamos aqui, doutoras em teologia, pois, indica que

\begin{abstract}
"é de desejar que muitos leigos consigam uma conveniente formação nas ciências sagradas e, não poucos entre eles, havendo necessidade, dediquem-se ex-professo a estes estudos e o aprofundem. Para que consigam desempenhar o seu dever, seja reconhecida nos fiéis, clérigos ou leigos, a justa liberdade de investigação e de pensamento, bem como a justa liberdade de exprimir as suas idéias com humildade e firmeza, nos assuntos de sua competência" ${ }^{\prime \prime}$.
\end{abstract}

Por isso, estamos aqui, para dizer nossa palavra com humildade, mas com firmeza.

Na Mensagem final do Concílio Vaticano II encontramos esta afirmação:

\begin{abstract}
"Chega a hora, já chegou a hora, em que a vocação da mulher se realiza em plenitude, a hora em que a mulher adquire no mundo uma influência, uma importância, um poder jamais alcançados até agora. Por isso, neste momento em que a humanidade conhece uma mutação tão profunda, as mulheres, cheias do espirito do Evangelho podem ajudar tanto a que a humanidade não decaia"17.
\end{abstract}

Esta afirmação recordada também pelo Papa João Paulo II na carta apostólica, Mulieris Dignitatem, sobre a dignidade da mulher, mostra o reconhecimento oficial diante do fenômeno da dignificação e promoção, da presença e do lugar da mulher na sociedade e na Igreja ${ }^{18}$.

Deixando ressoar na mente e no coração estas palavras voltamos nosso olhar para a América Latina de 1968.

\title{
3. Medellín: a "re-criação" do Vaticano II na América Latina
}

É impossível ir a um texto escrito há mais de 40 anos atrás, sem um olhar e uma pergunta de hoje. O que Medellín ainda nos ensina hoje? Nesta apresentação buscarei articular a eclesiologia latino americana desde Medel-

\footnotetext{
${ }^{16}$ GS 62 final, cf tb LG 37.

${ }^{17}$ Mensagem do Concílio às mulheres (8/12/1963).

18 JOÃO PAULO II, Mulieris Dignitatem, 15/08/1988.
} 
lín até Aparecida- com a perspectiva das mulheres, obrigatoriamente leigas, e também dos leigos.

A palavra chave para descrever 1968 era "mudança". A Igreja na América Latina neste contexto, vai, com entusiasmo, procurar re-criar o Concílio Vaticano II, adaptando-o ao seu ser e ao seu agir, e colocar em prática uma das suas intuições que não havia sido explicitada: a opção pelos pobres. A Teologia da Libertação na América Latina, utilizando o método da Ação Católica: Ver-Julgar-Agir, parte da situação de miséria e opressão em que viviam as maiorias deste continente, situação considerada "uma situação de pecado $^{19}$ ", procura entendê-la a partir das ciências sociais, busca interpretála à luz da Bíblia, para descobrir como atuar em vista da salvação integral das pessoas. Em conseqüência, começou uma caminhada no sentido de buscar ser "a voz dos sem voz", e de estar ao lado e lutando por aqueles e aquelas que os profetas do AT chamavam de "preferidos de Deus", os pobres, marginalizados, sofredores, enfim, todos aqueles e aquelas que tinham suas vidas diminuídas. O Deus, pai de Jesus Cristo não podia suportar tanto sofrimento para seus filhos e filhas (cf. Ex 3,8), como este nos revelou através de seu comportamento (cf. Jo 10,10). Portanto, a opção pelos pobres é teocêntrica $^{20}$ e cristológica, e não ideológica, como foi acusada de ser!

Pode-se afirmar que ocorre um "encontro entre a transformação social da América Latina e a transformação eclesial do Concílio"21. Num primeiro momento, os pobres são entendidos de forma anônima, e como objeto de solidariedade, agora, passam a sujeito de uma caminhada eclesial e social em defesa da vida diminuída. Desde dentro deste movimento, foram emergindo os rostos das mulheres, dos indígenas, dos afro-descendentes, que se tornavam visíveis e que apontavam para a necessidade de ir além de análises sócio-políticas-economicas, pois, a cultura também deveria ser levada em conta. Os empobrecidos culturais começam a lutar para fazer escutar suas vozes, e também se tornarem protagonistas.

A Conferência dos Bispos latino-americanos em Medellín foi um verdadeiro Kairós. A Igreja Católica na América Latina começou a realizar uma experiência de Êxodo, de saída da escravidão sócio-política-econômica, para uma libertação integral, que transformasse este continente numa realidade mais justa, mais de acordo com o projeto de Deus. É a hora da ação! Para vivê-la é preciso se colocar de forma corajosa e decidida no seguimento profé-

\footnotetext{
${ }^{19}$ Doc Méd. Paz I, 1.

${ }^{20}$ Cf. G. GUTIERREZ "La chiesa e i poveri visti dell'America Latina" in G.ALBERIGO, J_P JOSSUA, Il Vaticano II e la Chiesa, Brescia, 1985, p.260.

${ }^{21}$ S.GALILEA, curso sobre Eclesiologia, Quito 1973, p 90.
} 
tico de Jesus, inclusive desde uma perspectiva de valorização da ação política, que até mortes provocou, os mártires cujo sangue fermentou este solo.

A fundamentação cristológica do documento aponta para a necessidade antropológica de conhecer o homem e a mulher latinoamericanos, para conhecer Jesus.

Embora as mulheres só tenham sido mencionadas uma vez no documento: "a mulher reivindica sua igualdade, de direito e de fato, com o homem"- frase que aparece no documento Justiça ${ }^{22}$ ), sempre tiveram uma fé forte e sempre estiveram presentes na evangelização do continente, por isso, sentiram-se convocadas pela grande luta dos empobrecidos em prol de uma vida mais digna, para seus filhos e netos, e iniciaram uma participação distinta nas igrejas e na sociedade. Esta a atitude que demonstram nas Comunidades Eclesiais de Base, as CEBs, ${ }^{23}$, experiência nova que o Espírito Santo suscitou e que tanta esperança provocou na Igreja Latinoamericana. Nas CEBs organizavam-se Círculos Bíblicos, onde a escuta da Palavra de Deus levava a uma ação prática em favor da vida; uma catequese renovada pela vivência de novos ministérios, da prática da oração, da renovada prática sacramental, e além disso, através de cursos profissionalizantes, de fóruns de debates, de ações por melhoria de vida, de grupos de influência política e de outras atividades ligadas à prática social. Tudo isso era encabeçado pelos próprios membros das CEBs, leigos e leigas que, iam se tornando adultos na fé; e, em conseqüência, assumiam sua história e suas responsabilidades na Igreja, em comunhão com seus pastores, e no mundo para levarem a boa nova de Jesus.

No século XX, incontestavelmente o movimento feminista foi um dos movimentos mais revolucionários. As mulheres que tradicionalmente viviam mantidas no mundo privado, dentro das casas, para cuidar do lar e dos filhos começaram a participar no mundo do trabalho, nos movimentos sociais, reivindicando direito a voto e a voz na sociedade. As mulheres do primeiro mundo começavam a emergir reivindicando paridade de direitos com os homens na sociedade. Também nas igrejas, inclusive na Igreja Católica, especialmente as que participavam dos movimentos de Ação Católica (Jec, Joc, Juc) começaram a aparecer. Este emergência das mulheres no cenário público foi tão importante, que o papa João XXIII considerou este fato como um dos "sinais dos tempos", que desafiavam à Igreja Católica ${ }^{24}$, como uma realidade nova que precisava ser considerada.

\footnotetext{
${ }^{22}$ Med 1,2.

${ }^{23}$ Cf. Med 1,20; 15,10

${ }^{24}$ Cf. papa João XXIII, Encíclica Pacem in Terris, 11/04/1963.
} 
Por volta da época de Medellin, as mulheres nas igrejas na AL, começaram a refletir sobre sua situação e perceberam que não tinham uma identidade própria, sentiam-se comparáveis "a seres sem rosto", cujos traços a sociedade traçava, considerando-as seres frágeis, sensíveis, cheias de imaginação e até meio irracionais, incapazes de serem objetivas, muito emotivas e, feitas para cuidar da casa e das crianças; ao passo que, os homens sempre foram considerados racionais, objetivos e treinados para trabalhar no espaço público. Ao se darem conta desta realidade, procuraram romper com esta identidade estereotipada, passando a desconstruí-la e começando a realizar um protagonismo novo, onde ousavam dizer sua palavra própria, falar sobre sua distinta experiência de Deus e visão do mundo, a partir da sua própria subjetividade. Vão tomando suas vidas nas mãos, buscam formação e informação, começam a participar da sociedade, vão re-significando esta autoimagem negativa, e construindo outra, que possibilitasse sua cidadania plena. Iniciam com uma participação nos Círculos Bíblicos, em experiências bem simples como os Clubes de Mães, e aos poucos, partem para os movimentos sociais e políticos, por terra, moradia, contra a carestia, e especialmente, descobrem nas CEBs, um espaço novo e uma maneira distinta: de viver a fé articulada com a vida.

Medellín não refletiu de forma explícita sobre a sua eclesiologia, mas trabalha implicitamente com a categoria da "Igreja como sacramento universal de salvação". Jesus Cristo, sacramento do amor do Pai, se constitui para nós em sinal de salvação. A Igreja, sua continuadora no mundo, se reconhece no Vaticano II, também, como sinal e sacramento de salvação. Medellín, na continuidade do Concílio, se reconhece nesta perspectiva. Esta noção se articula com a de "mistério de comunhão", porque a comunhão é o projeto de Deus para os seres humanos, reunidos num "Povo de Deus" e em "comunidades ${ }^{25 \%}$. Esta Conferência acredita que a ação pastoral de toda a Igreja, destina-se a "levar o homem todo e todos os homens à plena comunhão de vida com Deus, na comunhão visível da Igreja ${ }^{26}$.

Embora a linguagem seja sexista, não impede que as mulheres comecem a exercer funções na pastoral, inclusive assumindo ministérios. O conjunto da evangelização enfatizava muito "a pessoa adulta na fé", bem formada e com capacidade para enfrentar desafios de forma crítica e corajosa ${ }^{27}$.

${ }^{25}$ Cf. A J de ALMEIDA, Teologia dos Ministérios não-ordenados na América Latina, São Paulo, Loyola, 1989, p.59.

${ }^{26}$ Doc. Méd.!5,9.

${ }^{27}$ Cf. a coleção de J.L. SEGUNDO, Teologia aberta para o leigo adulto, Buenos Ayres, Lohlé, 1976, e merece um elogio o empenho deste teólogo na formação dos leigos-as, não só através de grupos constantes, com os quais dialogava, como de cursos de fim-de-semana através de todo o continente latino americano. 
Em consequência, ocorre uma crescente valorização da presença dos leigosas que vivendo sua vida cristã com profundidade, participavam tanto na missão da Igreja, como na busca pela transformação do mundo ${ }^{28}$. Neste sentido, uma das marcas da eclesiologia latino americana será a questão dos carismas-ministérios, que emergia com força, e que aparece no documento "Pastoral de conjunto" A unidade na missão e a diversidade de ministérios para realizar a comum missão é afirmada também no documento "Movimento de Leigos $^{29}$ ". Trata-se de uma novidade, que rapidamente se estendeu por todo o continente ${ }^{30}$.

Como as mulheres foram exercendo estes ministérios, no concreto da vida, depois de Medellín vários encontros vão tratar sobre a questão dos novos ministérios que iam surgindo na AL, sob o sopro do Espírito de Deus. Em 1974, em Cumbayá, Equador, apareceu a questão do diaconato permanente, e a questão das mulheres e ministérios. A carta papal Ministeria Quaedam, recolheu e reconheceu esta experiência, por isso, criou novos ministérios a serem exercidos pelos leigos-as. A efervescência era muito grande, e a diversificação dos ministérios eclesiais aparece como uma resposta para a Igreja fazer face às necessidades que surgiam, embora, esta estrutura carismático-ministerial já houvesse existido nas comunidades paulinas ${ }^{31}$. Os bispos exerciam sua criatividade e buscavam meios de descobrir o verdadeiro lugar das mulheres, especialmente, das religiosas, que haviam deixado suas grandes casas e colégios, para inserirem-se nos meios populares, dentro das atividades pastorais da igreja. Os documentos mencionam as Delegadas da Palavra, assim como outras atividades e reconhecem que foram as mulheres que conservaram a fé de nossos povos, como educadoras, companheiras e artífices da unidade ${ }^{32}$. De maneira forte aparecia, também, a necessidade do ministro solteiro ou casado, que pudesse celebrar a Eucaristia, (problema que continua sem solução, e é enfatizado em cada Encontro Inter eclesial das CEBs).

Depois desta breve síntese, poderemos elencar como marcas de Medellín: a opção pelos pobres, Povo de Deus que assume uma caminhada, em comunhão com seus Pastores, vivendo uma novidade de protagonismo, através dos carismas e ministérios suscitados pelo Espírito Santo, realizando a experiência das CEBs, buscando articular fé e vida, como meio de lutar por vida mais digna e mais condizente com a vontade de Deus.

\footnotetext{
${ }^{28}$ Doc. Méd. 11,10

${ }^{29}$ Cf. A. J. ALMEIDA op cit. p.61-62.

${ }^{30}$ Cf. M. O. SOUZA NETO, Maturidade Eclesial, comunhão e ministérios, tese doutoral defendida na PUC-Rio em 1994, com farta documentação.

${ }^{31}$ Cf. E. SCHILLEBEECKX, Por uma Igreja mais humana, São Paulo, Paulinas, 1986, p.56-80;

${ }^{32}$ A. J. ALMEIDA p. 82.
} 
De Medellín (1968) a Puebla (1979) viveu-se uma década de muito compromisso na AL. Enrique Dusserl a chama de "década de sangue" por causa dos inúmeros mártires, conhecidos e desconhecidos que deram sua vida, no seguimento de Jesus, por conta de seu compromisso de fé, em benefício de uma vida melhor para os mais desfavorecidos, no pro-seguimento de sua causa.

\section{Comunhão e participação: Puebla (1979)}

Em 1979, acontece a conferência de Puebla, no México, que é a continuação de Medellín. Na verdade, Medellín e Puebla se completam. Dentro de um quadro de piora de situação sócio-política-econômica, onde as ditaduras militares recrudecem- no Brasil, o AI 5 em dezembro de 68 trouxe muita violência, arbítrio, tortura. No Chile ocorre a queda de Allende por obra da CIA. $\mathrm{Na}$ Argentina e Uruguai ocorrem sequestros, torturas, desaparecimentos.

Em vista disso, como marca de Puebla aprofunda-se o compromisso com o povo e a luta pela libertação, tendo como conseqüência muita perseguição e mortes $^{33}$. Afrontas a leigos-as, a padres e inclusive a bispos, com campanhas de difamação.

Porém, também surgem algumas novidades boas, como a caminhada ecumênica através de um trabalho conjunto, a pastoral da Terra, a pastoral indigenista, e as CEBS que continuam e crescem como um sinal de esperança promissor.

Puebla foi mais conflitiva que Medellín, tendo em conta a situação em que se vivia, mas, afirmou uma clara opção pelos pobres ${ }^{34}$, e pelos jovens, opção que ficou em segundo plano.

O documento busca enfocar a totalidade da evangelização na América Latina. É bom lembrar que a Igreja estava envolvida com o tema da Evangelização devido ao Sínodo de 1974 e à carta encíclica Evangelii Nuntiandi de 1975.

Com relação à eclesiologia oferece uma grande síntese; continua com a perspectiva de uma Igreja sacramento de salvação vivida em comunhão e participação, retomando a perspectiva da igreja primitiva. Uma igreja alegre e missionária.

Não podendo ocultar o protagonismo das mulheres, Puebla vai explicitar mais a questão da mulher. Na verdade, em meados dos anos 70 , por ocasião do Ano Internacional da Mulher, tem início em nossa Igreja uma reflexão

\footnotetext{
${ }^{33}$ Em 1975 é assassinado o Pe. Rodolfo Lukenbein e o índio Bororo Simão, em Minas Gerais; também o Pe. João Bosco Penido Burnier em Mato Grosso, e foi seqüestrado D. Adriano Hipólito, bispo de Nova Iguaçu, RJ.

${ }^{34}$ P. 1134
} 
mais sistemática e abrangente sobre a mulher, partindo de nossa realidade, e levando em conta os diferentes movimentos feministas já existentes. A reflexão sobre a situação das mulheres, aparece dentro do debate sobre a evangelização, o que lhe traz características especiais. O texto denuncia a marginalização da mulher como "conseqüência de atavismos culturais" e reconhece sua quase total ausência na vida política, econômica e cultural ${ }^{35}$. As mulheres aparecem de maneira positiva no contexto social ${ }^{36}$, na vida política, econômica e cultural; embora, algumas vezes fosse apresentada como objeto de consumo ${ }^{37}$. O documento denuncia também, que devido à situação econômica angustiosa a prostituição tem aumentado ${ }^{38}$; e denuncia o desrespeito ao cumprimento das leis de proteção à mulher ${ }^{39}$; bem como, denuncia a sobrecarga de trabalho com dupla ou tripla jornada, muitas vezes, abandonada pelo marido ${ }^{40}$. No entanto é valorizada sua contribuição concreta à evangelização ${ }^{41}$, e a possibilidade de receber ministérios não ordenados ${ }^{42}$, sublinha o papel da mulher como mãe, defensora da vida e educadora do $\operatorname{lar}^{43}$; enfatiza a promoção da mulher como "sinal dos tempos" 44 , assim como sua contribuição própria para participar na transformação da sociedade ${ }^{45}$. Explicita que o anseio da mulher por sua promoção se situa no contexto dos problemas importantes, como as migrações, a invasão de seitas, a influência dos Meios de Comunicação Social, aponta seu surgimento no mundo operário ${ }^{46}$; explicita a crise de identidade da juventude feminina $^{47}$; e a responsabilidade insubstituível da mulher na humanização dos processos transformadores ${ }^{48}$.

Na Igreja, afirma Puebla, não tem havido suficiente valorização da mulher, e no nível das iniciativas pastorais, sua participação é ainda escassa ${ }^{49}$.

A questão da mulher, que foi portanto, bastante visibilizada foi fruto da participação das mulheres, não só nos movimentos sociais e populares,

\footnotetext{
${ }^{35}$ P. 834-837. Cf. D. BRUNELLI, Libertação da Mulher. Um desafio para a Igreja e a Vida Religiosa da América Latina, Rio de Janeiro, CRB, 1988, p. 19.

${ }^{36}$ P. 834-837; 846-848; 419; 1174; 1219.

${ }^{37}$ P. 834.

${ }^{38}$ P. 835.

${ }^{39}$ P. 836.

${ }^{40}$ P. 837.

${ }^{41}$ P. 834 s.

${ }^{42}$ P. 835.

${ }^{43}$ P. 846.

${ }^{44}$ P. 847.

${ }^{45}$ P. 848 .

${ }^{46}$ P. 419.

${ }^{47}$ P. 1174.

${ }^{48}$ P. 1219.

${ }^{49}$ P. 839.
} 
mas também nas igrejas, nos movimentos, nas paróquias e nas pastorais. Nas CEBs que se constituem no espaço privilegiado, elas participam como coordenadoras, na catequese, na liturgia, na leitura da Palavra, exercendo vários ministérios. Apesar da linguagem sexista, Puebla oferece elementos que contribuirão decisivamente para o surgimento da teologia feminista na América latina ${ }^{50}$.

O caminho para o protagonismo dos leigos-as continua com o desenvolvimento dos ministérios, com a união fé-vida, tal qual vivida nas Cebs. Esta caminhada vai se tornando mais forte e visível até a próxima conferência em Santo Domingo.

\section{Santo Domingo (1992): por uma evangelização inculturada}

A Conferência de Santo Domingo teve vários entraves e uma influência muito forte de Roma, por isso produziu um documento desigual. A melhor parte, e que deve servir de chave de leitura é a segunda parte, n.II: que trata da promoção humana, e reitera a opção evangélica pelos pobres ${ }^{51}$, assim como, dá continuidade à trajetória eclesial latinoamericana.

Embora preparado por documentos anteriores ${ }^{52}$, que tomam como ponto de partida a realidade vivida, no nosso caso, pelas mulheres, a conferência busca iluminá-la teologicamente ao mesmo tempo que o documento vai propondo em seguida, pistas pastorais, para atuar modificando a realidade, buscando fortalecer as tendências libertadoras. Estes conteúdos influenciam o texto sobre as mulheres, assim como os textos trabalhados ao longo da conferência, embora tenham sido modificados na última redação da comissão Mulheres ${ }^{53}$.

Considerando-se as mudanças substanciais, que o documento apresenta a respeito da direção prévia que caracterizou o magistério latinoamericano, podemos afirmar que a visão que apresenta o documento de Santo Do-

\footnotetext{
${ }^{50}$ Cf A M TEPEDINO, La mujer y la teologia en America Latina, in A M TEPEDINO\& M P. AQUINO, Entre la indignación y la esperanza, Teología feminista latinoamericana, Asociación Ecuménica de Teólogos y Teólogas del tercer mundo- Bogota, Indo American Press, 1998, p.9-35; tb in A M BIDEGAIN, Mulheres e controle religioso na America Latina, Cehila-Vozes, 2000.

${ }^{51}$ S.D. $178,180$.

52 Documento de Santafe, de Bogotá " La mujer en la Iglesia y la Cultura Latinoamericana", abril de 1992.

${ }^{53}$ A comissão era composta de 11 pessoas, entre elas 4 bispos (2 mexicanos, um salvadorenho, um brasileiro D. Angélico Sândalo) 4 religiosas, 2 leigas, e um bispo presbiteriano como observador. Chama atenção o numero de mulheres (6). Colaborei assessorando esta comissão.
} 
mingo é em geral, bastante positiva ${ }^{54}$, apresentando três blocos: um princípio fundamental-que oferece o ponto de partida para interpretar a realidade vivida pelas mulheres, ao qual a Igreja deve responder: trata-se de uma realidade que contraria o projeto de Deus, pois, viola os direitos humanos básicos ${ }^{55}$ :

\begin{abstract}
"não somente pelo terrorismo, pela repressão, pelos assassinatos, senão também pela existência de condições de extrema pobreza e de estruturas econômicas injustas que originam grandes desigualdades... Merecem ${ }^{56}$ uma denúncia especial as violências contra os direitos das crianças, das mulheres e dos grupos mais pobres da sociedade. Nesta realidade, a Igreja se sente chamada a descobrir o rosto de Jesus Cristo nos rostos sofredores dos pobres... nos rostos sofridos das mulheres humilhadas e desprezadas, que desafiam ao Povo de Deus a uma conversão pessoal e eclesial ${ }^{57}$.
\end{abstract}

O segundo bloco: a situação das mulheres e os compromissos pastorais $^{58}$. Esta seção, não foi incorporada nem na seção sobre os leigos (em geral), nem reduzida à seção sobre a família, está situada na seção sobre as estruturas eclesiais que foi chamada "Na unidade do Espírito, em diversidade de carismas e ministérios", dando-lhes desta forma, um espaço e uma visibilização própria. Também utiliza a linguagem inclusiva.

Santo Domingo assinala um "novo sinal dos tempos",59, a crescente consciência na sociedade e na igreja sobre a igual dignidade e os direitos equivalentes entre homens e mulheres ${ }^{60}$, adquiridos em Cristo. Também reconhece a força das mulheres na construção do mundo e das comunidades eclesiais ${ }^{61}$. No entanto, também observa que "este reconhecimento se choca escandalosamente com a freqüente realidade de sua marginalização, dos perigos aos quais se submete sua dignidade, da violência da qual muitas vezes é objeto $^{62}$. Por conseguinte, afirma o documento que a Igreja deve enfrentar esta situação na nova evangelização sendo "promotora decidida $e$

${ }^{54}$ Cf. M P AQUINO, Santo Domingo: La visión sobre las mujeres latinoamericanas, in Reflexión y Liberación 19, (Santiago, Chile), 1993, p.39-50.

${ }^{55}$ S.D. 164.

56 S.D. 178.

57 S.D. 167.

${ }^{58}$ S.D. 104-110.

${ }^{59}$ S.D. 164, 167.

${ }^{60}$ S.D. 105.

${ }^{61}$ S.D. 104-106.

62 S.D. 106. 
ativa da dignidade da mulher, o que supõe aprofundar no papel da mulher na igreja e na sociedade.

As linhas pastorais de ação enfatizam a necessidade de fomentar uma atitude crítica diante das mensagens, dos estereótipos, dos valores, da linguagem, dos símbolos e das imagens que se transmitem na sociedade e na Igreja $^{63}$ denunciar as violações às mulheres latino americanas e caribenhas, sobretudo, os aspectos que atentam contra sua vida e dignidade como mulheres $^{64}$, promover a formação integral do clero e de toda a comunidade, para que se reconheça efetivamente os direitos e a dignidade comum de mulheres e homens ${ }^{65}$, impulsionar uma pastoral que apóie caminhos não redutivos das mulheres na educação, na leitura da Escritura, e também no campo social e político; na tomada de decisões em todos os âmbitos, bem como, contar com a liderança feminina na organização e animação da nova evangelização ${ }^{66}$.

Importante é o terceiro bloco: a família patriarcal e a vocação da mulher onde aparece o seguinte ${ }^{67}$ "frente a posições reducionistas sobre a natureza e missão da mulher, recorre ao documento de Puebla, para afirmar que a Igreja quer propor a 'doutrina evangélica sobre a dignidade e vocação da mulher' sublinhando seu papel de mãe, defensora da vida, e educadora do lar". Este texto, sim, é redutor da vocação das mulheres, como foi imposto pela cultura patriarcal, que sublinha apenas sua capacidade biológica para a maternidade. Esta visão redutiva segue a lógica de toda a seção sobre a família ${ }^{68}$.

\section{Aparecida (2006)}

Parte da tomada de consciência (ver) da situação precária que afeta a dignidade das mulheres ${ }^{69}$ : violência, tráfico, escravização, assédio sexual; colocando em relevo os rostos sofridos das mulheres excluídas pelo sexo, raça, idade, condição social ${ }^{70}$. Reconhece a importância da irrupção de novos atores sociais: indígenas, negros e mulheres, que fortalecem a democracia participativa $^{71}$, enfatiza que mulheres e homens negros recuperam sua identidade $^{72}$. Um ganho é o fato de que a linguagem é inclusiva.

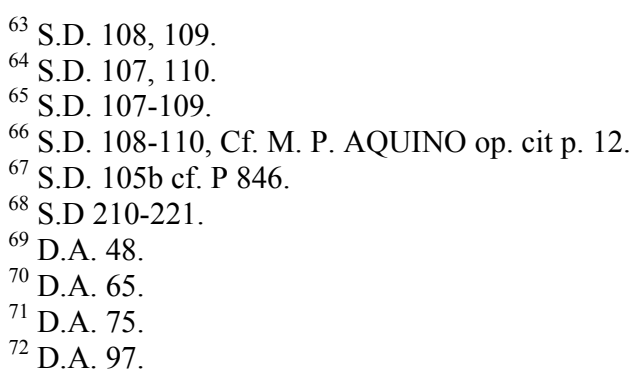


Na segunda parte, dentro da seção "A Boa Nova da dignidade humana" aparecem mulheres e homens lutando pela dignidade da humanização ${ }^{73}$, na formação da família fundada no sacramento do matrimonio ${ }^{74}$ e que tem seu fundamento simbólico na relação Yahveh- povo, e Cristo-Igreja ${ }^{75}$, como seguidores-as de Jesus, testemunhado sua fé. As mulheres são chamadas a ser discípulas e missionárias a serviço da vida plena, tendo como exemplo as mulheres que, como os evangelhos nos contam, estiveram presentes e atuantes no movimento de Jesus ${ }^{76}$. A participação na luta pela justiça realizando sinais do Reino de Deus, lutando contra os ídolos do poder, da riqueza e dos prazeres efêmeros, anunciando o evangelho da dignidade humana ${ }^{77}$. E junto com os homens participando do bem comum e da globalização da solidariedade.

No capítulo: Família, pessoas e vida ${ }^{78}$ apresenta uma seção sobre as mulheres, onde desde a antropologia cristã dignifica as mulheres, lamenta a mentalidade machista, que as desvaloriza, valoriza sua participação na vida social e eclesial, escuta o clamor das mulheres silenciadas, garante sua presença nos ministérios, valoriza sua transmissão da fé, e conclama à participação plena em todos os setores da vida. Nesta seção, também fala do pai de família ${ }^{79}$, chamando-o à responsabilidade, criticando-o pelo afastamento dos valores evangélicos: com terríveis consequências como o alcoolismo, violência familiar, infidelidade, abuso sexual, drogas etc. Reconhece que os homens são muito cobrados pela sociedade, especialmente com relação ao seu papel como "provedor", conclama que aprofundem seu papel na família, para conhecer sua situação atualmente, influenciada por novos modelos culturais.

A eclesiologia do documento de Aparecida mantêm a mesma perspectiva de Medellin, de opção pelos pobres, não como uma decisão da razão e da vontade, mas como fruto do afeto, do estar junto. Desta maneira, a Igreja quer ser a "casa dos pobres", uma Igreja Samaritana, que sai em auxílio dos sofridos-as da sociedade, os "novos excluídos", quer ser, portanto um sinal concreto de salvação.

\section{Conclusão}

Medellín propôs uma igreja "sinal e instrumento de salvação", vivida como Povo de Deus em comunhão, valorizando as comunidades. E nestes

\footnotetext{
${ }^{73}$ D.A. 105.

${ }^{74}$ D.A.116-117.

${ }^{75}$ D.A 433 .

${ }^{76}$ D.A. 353 .

${ }^{77}$ DA. $382,387$.

${ }^{78}$ D.A. $451-457$.

${ }^{79}$ D.A. $459-463$.
} 
mais 40 anos, e através de muitos percalços, tais como, uma visão mais conservadora, mais intimista, menos comprometida, ela continua a marcar um rumo eclesial, que talvez, hoje, não apareça tanto, mas, que continua vivo e atuante a inspirar a mulheres e homens no seu compromisso pelo Reino. As conferências seguiram este mesmo rumo. Aparecida é um chamado à missão realizada de outra forma, talvez, mas em benefício dos preferidos-as de Deus. Os pequenos grupos, as CEBs as novas comunidades e movimentos eclesiais são espaços privilegiados para ser um povo de Deus, formado de discípulos-as e missionários-as, buscando viver uma espiritualidade do seguimento de Jesus, que se coloque à escuta dos apelos de Espírito Santo, no nosso tempo, tanto dentro da Igreja como na sociedade, dentro de um processo mistagógico que nos faça aprofundar no Mistério e também colabore para uma formação integral que reconheça e respeite os processos de cada pessoa.

Nestes mais de 40 anos muita coisa mudou para as mulheres. Algumas teólogas, entre elas a filósofa argentina Maria Lugones afirma que as mulheres descobriram um modo de trabalhar "desde dentro/within" e "entre/in between", que eu traduziria como "nas brechas". Desta forma, fomos construindo um protagonismo próprio e descobrindo novos mundos. Temos rostos diferentes: negros, brancos, indígenas. Participamos nos movimentos populares, nas Cebs, nas novas comunidades, nas escolas, nas universidades. Coordenamos, animamos, preparamos e realizamos liturgias, somos ministras da Eucaristia, catequistas, professoras, pregadoras de retiros etc. Estamos presentes nos mais diversos setores da vida da Igreja e da sociedade. Estamos nas paróquias, nas pastorais, nos movimentos, nos conselhos, nos seminários, nos institutos teológicos, nas faculdades de Ciência da Religião e de Teologia; nas fábricas, nos escritórios, nas escolas, nos hospitais, na política. Indubitavelmente, se alguns não reconhecem o bem que fazemos, não desanimamos e continuamos a estar presentes e atuantes nesta Igreja santa e pecadora, buscando construir novas relações interhumanas, convivências plurais, apostando que estas nos ajudarão a entrar em consensos éticos, que contribuirão para uma nova ordem mundial. Medellín, seguindo a inspiração da GS nos fez sonhar com um mundo de solidariedade e paz, e nada tão necessário ao momento que estamos vivendo. Viver a globalização da solidariedade, inspiradas pelo Espírito da vida é a missão a que fomos chamadas! 


\section{Referências Bibliográficas}

ALMEIDA A J. Teologia dos ministérios não ordenados na América Latina, São Paulo, Paulinas, 1989.

AQUINO M. P. Santo Domingo: La visión sobre las mujeres latinoamericanas, in Reflexion y Liberación, Santiago, Chile, 1995, p. 39-50.

BORÒBIO D. Misión y ministérios laicales, Salamanca, Sigueme, 2001, p. 97

BRUNELLI D. Libertação da mulher. Um desafio para a Igreja e a Vida Religiosa da América Latina, Rio de janeiro, CRB, 1988 p. 19.

GUTIERREZ G. La chiesa e Il poveri visti dal'America latina in G. ALBERIGO \&J.P.JOSSUA, Il Vaticano II e La Chiesa, Italia, Brescia, 1985, p.260.

LAFONT G., Imaginar a Igreja Católica, São Paulo, Loyola, 2008.

RUBIN G. The traffic on women. Notes on the political economy of sex, 1975.

SCHILLEBEECKX E. Por uma Igreja mais humana, São Paulo, Paulinas, 1998. SEGUNDO J.L. Teologia abierta al laico adulto, Buenos Aires, Lohlé, 1976.

SOUZA NETO M. O. Maturidade eclesial, comunhão e participação, tese doutoral apresentada na PUC-Rio em 1994.

TEPEDINO A M. La mujer e la Teologia en América Latina in TEPEDINO A.M. \& AQUINO M. P. Entre la indignación y la esperanza. Teologia feminista latinoamericana, Colombia, Indo-American Press, 1998, p.9-35

DOCUMENTOS DO MAGISTÉRIO:

JOÃO XVIII, Pacem in Terris (1963)

JOÃO PAULO II, Christifideles laici (1988)

, Mulieris dignitatem (1963)

CONCİLIO VATICAO II:

Lumen Gentium, $n^{o s} 30,31,32,33,57$

Gaudium et Spes, $n^{o s}$ 3, 9, 29, 47-52, 60, 62

Ad Gentes, $n^{o s}$ 2, 3, 9.

Mensagem do Concílio às mulheres, 15/08/1963

Documento de Medellin. A Igreja na atual transformação da America Latina, Petrópolis, Vozes, 1968.

Documento de Puebla. A Evangelização no presente e no futuro da América latina, Petrópolis, Vozes, 1979.

Documento de Santo Domingo. Nova Evangelização, Promoção Humana, Cultura Cristã,São Paulo, Paulinas, 1992

Documento de Aparecida. Texto conclusivo da V Conferência geral do Episcopado Latino-americano e do Caribe, São Paulo, CNB, Paulus, Paulinas, 2007.

Documento da Santafe de Bogota La mujer em La Iglesia y La Cultura latinoamericana, abril de 1992. 


\title{
Resumo
}

Este artigo tem por objetivo refletir sobre a caminhada da Igreja da América Latina através das suas conferências episcopais: Medellín (19680, Puebla (1979), Santo Domingo (1992) e Aparecida (2007), apresentando os marcos principais, a trajetória vivida e busca enfatizar, principalmente a participação e valorização das mulheres em seu protagonismo eclesial e social. Acentua a perspectiva da Igreja como sacramento de salvação como marco principal, seguindo a concepção do Concílio Vaticano II.

Palavras-chave: Eclesiologia, America Latina, Conferências Episcopais, Protagonismo das mulheres.

\section{Resumé}

Cet article a pour bût analiser le chemin realizé para 1'Èglise latino- americaine à travers de ses Conférences Episcopales: Medellin (1968), Puebla (1972), Santo Domingo (1992) et Aparecida (2007), présentant les marques principales, le chemin vécu, 1 ' accentuation sur la participation des femmes dans son protagonisme éclesial et social. L'article veut aussi mettre l'accent sur la perspective de L'Eglise comme Sacrement de Salvation suivant la conception du Concile Vatican II.

Mots clés: Eclesiologie, Amerique Latine, Conferences Episcopales, Participation des femmes.

\author{
Ana Maria L. Tepedino \\ Doutora pela PUC-Rio \\ Professora do Departamento de Teologia da PUC-Rio \\ E-mail: tepedino@puc-rio.br \\ Artigo Recebido em 10/11/2010 \\ Artigo Aprovado em 15/12/2010
}

